\title{
Baltic amber inspection: micro-macro-structural and luminescent analysis
}

\author{
Iana Verkhovskaia ${ }^{1,2}$ \\ ${ }^{1}$ Saint Petersburg State University of Architecture and Civil Engineering, 190005, Saint Petersburg, \\ Russian Federation \\ ${ }^{2}$ ITMO University, 197101, Saint Petersburg, Russian Federation
}

\begin{abstract}
The solution of the problem of amber (succinite) flaw detection by microscopic analysis and luminescent analysis of amber macrostructure is proposed. The proposed method allows to obtain a rapid analysis of the defective state of the material structure. Given the growing demand for the use of such materials on an industrial scale and the insufficiency of existing methods, the proposed method may be a new solution to the problem of flaw detection. The basis of the proposed method for studying the macro structure of amber is transmission spectroscopy, luminescent analysis method. Samples of raw, heat-treated and pressed amber of the Palmniken Deposit obtained in the city of Kaliningrad of the Russian Federation were used as objects of research. Samples of different degrees of transparency and heat treatment were selected. It is established that the distinctive luminescence intensity at the defect boundaries is a characteristic of the presence of internal defects of the material and indicates the location of internal fractures, microcracks and other mechanical damage. The proposed method may be of interest in the theory of knowledge of materials science, research related to the processes of flaw detection of organic materials.
\end{abstract}

\section{Introduction}

Amber is a unique material of fossil resin, which is more than 30-90 million years old. Amber is valued in many fields of science and technology due to its unique physical and chemical properties, and in the arts and crafts-for its color, beauty and has been used as a precious stone since ancient times. Amber deposits are found all over the world and the most famous deposits are from the basins of the Baltic sea, the Dominican Republic, Sicily, Borneo, Spain, etc [1].

At present, more than a hundred deposits of fossil amber-like resins, as well as similar modern formations, about $90 \%$ of all world reserves of which are located in the field of the Kaliningrad region [2]. The periods of formation and distribution of amber-like fossil resins on the Earth, the variety of names of which, as a rule, is connected with the places of finds, are established [3-5]: 
- Cenozoic era (10-65 mill. years ago): Aral, Baltic, white sea, Burmese, Mexican, Romanian, Sakhalin, Sicilian, Ukrainian deposits;

- Мез Mesozoic era (65-135 mill. years ago): Azerbaijani, Ararat, Armenian, Eastern-Chukchi, Canadian, Moravian, American, Taimyr deposits.

As a rule, the initial composition, conditions, Deposit, time of origin of amber-like resins affect the physical, chemical, mechanical properties and acquire distinctive direct and indirect signs-attributes that allow to make the most complete and informative systematization or classification [6].

For example, when studying the morphology of amber, the shape of the pieces and their textural features, mechanical properties, in particular hardness measurements, allow us to judge the time period and conditions of its formation, it was found that the viscosity of the resin and the speed of its solidification have a direct influence on the transparency and formation of the thickness of the weathering crust over the entire surface. This circumstance served the formation and wide application of amber classification by transparency (transparent, smoky, bastard, bone, foamy), however, without taking into account the Deposit, conditions, features of formation, flowing physical and chemical processes and influences, which does not allow for a complete analysis and systematization.

From the presented studies the color characteristics of the amber [2] it follows that the color palette is a wide range of colors and has a primary color, which is directly dependent on the composition and changes in the structures of molecules to the nature of the dispersion of the white light and the presence of inclusions, the secondary formed as a result of oxidation and exposure to the environment and temperature. This issue also requires detailed study.

The growing interest and demand for raw amber industry, the depletion of raw amber, combined with the increased cost of materials contributes to the development of such areas as examination and evaluation of the quality of the materials of the amber industry.

Meanwhile, the analysis of defects in the macrostructure of amber products is based on organoleptic and laboratory destructive methods, which in some cases is uninformative, and in others is unacceptable. However, studies of the physical, chemical, mechanical and technological properties of amber are limited by the low availability and high cost of modern laboratory equipment, while the choice and quality of materials in the manufacture of the product remains one of the most important aspects [7].

The development of methods and techniques of non-destructive testing, as well as the qualitative development of the laboratory complex contributes to the development of scientific research in the field of materials science, in particular the amber industry. It should be noted that non-destructive methods of assessing the quality of amber raw materials are very relevant, so the development and creation of scientific and methodological recommendations for flaw detection of amber products is an urgent problem.

As a rule, in macroscopic studies of amber materials, optical methods are used on the same type and different in structure samples from different parts of the object to study the internal structure in relatively small areas of the object, while visual assessment does not allow to assess the quality of the structure of the material. At the same time, the quality of the material structure is one of the most important properties, since underestimation of the consequences of internal stresses of the material and hidden defects leads to large losses in the processing of amber raw materials and marriage of amber products.

In this context, it is important to study and understand the structure of natural polymer materials [8], which show very interesting characteristics in terms of optical properties, namely fluorescence, birefringence, transparency in UV radiation combined with mechanical and chemical resistance. 
In this context, it is important to study and understand the structure of natural polymer materials, which show very interesting characteristics in terms of optical properties, namely fluorescence, birefringence, transparency in UV radiation combined with mechanical and chemical resistance.

It is known that amber is a high-molecular polymer compound of organic origin. Due to its high physical and mechanical properties, amber and amber-like resins are widely used in various fields of industry. Widespread use in industry, in particular instrument-making, served to study the physical, mechanical, chemical properties, which also contributed to the further development of interest of specialists in various fields to this material.

In particular, the study of the chemical nature of amber [9] established characteristic features, namely the presence of volatile aromatic (essential) oils, succinic acid and $90 \%$ insoluble residue, including succinic acid salts- succinates, which is part of the ester of succinosilvinic acid $\mathrm{C}_{4} \mathrm{H}_{26} \mathrm{O}_{2}$. Actually, amber is often called succinite, meaning it highquality amber [10]. By K. Plonait and FR. Gelm in the study of the morphology of amber established the fact of dependence of the increase in the amount of succinic acid in the" weathered " surface crust, which served to further study and determine the dependence of the chemical composition on geographical affiliation.

Amber is known to be optically isotropic, but its refractive index is unstable and varies in the range from 1.535 to 1.561 . A direct dependence of the refractive index on the transparency and the degree of weathering, which increases from the center of the sample to its periphery, is established. The structure of amber is heterogeneous and its structure depends on the conditions of formation of amber resin and fossilization [11].

It is known that as a result of absorption of ultraviolet radiation, amber luminesces [12]. there is a hypothesis about the dependence of the luminescence intensity on the molecular structure of the material and on the degree of translucency. It is established that transparent amber has a blue glow of different intensity, smoky-pale blue glow; bastard-matte white with a noticeable yellowish tint, bone, foamy-white glow with a matte, white and bluish tint or bluish-white, yellowish-white. Therefore, it can be assumed that the intensity of luminescence has a direct dependence on the degree of transparency, i.e. weakens with decreasing transparency, namely, that in the process of weathering transparent amber become brownish, not transparent, and bone-light and reddish-brown, translucent. First Liu ministerul various shades of brown, others are orange-yellow or yellowish-orange. But this question is not studied in detail.

It was found that when amber comes into contact with air, its surface is oxidized by saturation with oxygen and a decrease in the content of other components, forming a "weathered" surface crust, which eventually builds up from the inside from the periphery to the center, outside it flakes off and gradually falls off. Its maximum thickness can be up to 2-4 $\mathrm{mm}$ according to various data, and the speed depends on the conditions of intensification of the oxidation process of amber, for example, in dry sandy soil saturated with atmospheric air, under the influence of ultraviolet rays and temperature influence. It is known that oxidation processes on the surfaces of products subjected to machining, including polishing, are not marked for 5 years, but are detected only after 10-15 years.

\section{Materials and Methods}

Samples of raw, heat-treated and pressed amber (succinite) from the Palmniken Deposit in Kaliningrad of the Russian Federation were selected as the material basis of the experimental study.

The first stage of the study was microscopic examination of succinite samples of the Palmniken Deposit (Table 1). 
Table 1. Morphology samples of succinite of Palmniken Deposit for microscopy

\begin{tabular}{|c|c|c|c|c|c|}
\hline \multirow{3}{*}{$\mathrm{n} / \mathrm{a}$} & \multicolumn{4}{|c|}{ Description } & \multirow{3}{*}{ Samples photos } \\
\hline & \multicolumn{4}{|c|}{ Morphology } & \\
\hline & description & $\begin{array}{l}\text { Dimensio } \\
\mathrm{ns}, \mathrm{mm}\end{array}$ & Color & $\begin{array}{l}\text { Transparency, } \\
\text { Shine }\end{array}$ & \\
\hline 1. & $\begin{array}{l}\text { Raw shard, } \\
\text { transparent, } \\
\text { uniform trans- } \\
\text { parency, }\end{array}$ & $3 \times 3 \times 1$ & Yellow & $\begin{array}{l}\text { Transparent, } \\
\text { chipped glossy }\end{array}$ & \\
\hline 2. & $\begin{array}{l}\text { Raw shard, } \\
\text { transparent, } \\
\text { cloudy }\end{array}$ & $3 \times 8 \times 1$ & Yellow & $\begin{array}{l}\text { Cloudy, } \\
\text { chipped glossy }\end{array}$ & 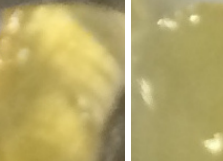 \\
\hline 3. & $\begin{array}{l}\text { Raw shard, } \\
\text { translucent, } \\
\text { cloudy }\end{array}$ & $3 \times 5 \times 1$ & Yellow & $\begin{array}{l}\text { Translucent, } \\
\text { chipped glossy }\end{array}$ & \\
\hline 4. & $\begin{array}{l}\text { Raw shard, } \\
\text { opaque, bastard }\end{array}$ & $9 \times 9 \times 1$ & $\begin{array}{l}\text { Light } \\
\text { yellow }\end{array}$ & $\begin{array}{l}\text { Opaque, } \\
\text { chipped glossy }\end{array}$ & \\
\hline
\end{tabular}

The studied samples were not subjected to special sample preparation, in addition, chips with a thickness of not more than $1.5 \mathrm{~mm}$ were mechanically removed in order to preserve the morphology and structure of amber.

The microscopy study was carried out on a confocal microscope Leica DMLM with a resolution of $<1$ microns, the work is carried out with illumination in reflected light with lenses 5x, 20x, 50x and 100x. Laboratory equipment is a complex spectrometer Renishaw InVia Reflex and includes a confocal microscope Leica DMLM with a resolution of $<1$ microns, the work is carried out with illumination in reflected light with lenses $5 \mathrm{x}, 20 \mathrm{x}, 50 \mathrm{x}$ and 100x, long-focus 20x and 50x, UV lenses 15x and 40x, as well as a trinocular tube with 2 eyepieces and a video camera. The accompanying equipment includes an automated XYZ-table allowing to work in the "mapping" mode, a set of polarizers and analyzers for each wavelength and visible light, a line Focus system For working in the UV, visible and close ranges, a high-temperature subject table (up to $1500^{\circ} \mathrm{C}$ ), A microstathe cryostat for working with samples in the range of 2.2-500 K and a system of direct display of signals.

The second stage was the study of luminescent properties of amber.

The study was conducted using the universal video spectral comparator "Regula" $4305 \mathrm{M} / \mathrm{MH}$. A source of excitation light for photoluminescence were used as radiation sources filters the visible region with a band 390-410 nm , 440-460 nm and 460-490 nm, $490-520 \mathrm{~nm}, 520-550 \mathrm{~nm}, 580-600 \mathrm{~nm}, 605-620 \mathrm{~nm}, 615-645$ and camera filters UV pass with strip 450-1100 nm, and an infrared pass with threshold $870 \mathrm{~nm}, 940 \mathrm{~nm}$. Registration of the results was carried out on a specialized, adapted PC SOFTWARE with full integration into the software "RegulaForensicsStudio". 
To obtain reliable results, the reference and test samples were in exactly the same conditions during the analysis (excited by the same source, had a strictly fixed location in the installation).

The physical basis of luminescence analysis is that the optical properties of luminescent polymer materials can be described by a number of characteristics: absorption and luminescence spectra, luminescence polarization, luminescence yield, duration of the excited state of molecules, the law of luminescence attenuation and thermal emission curves. Obtaining qualitative and quantitative characteristics of luminescence analysis is possible in the study of changes and variations of intensity parameters and forms of luminescence spectra based on Sitox-Lommel laws and Vavilov's law [13].

Luminescent analysis has a number of features that distinguish it from all other types of analysis, namely high sensitivity, also an important advantage is that before the study does not require special preparation and processing of samples. With its help, it is possible to detect the presence of substances with a concentration of $\sim 10-10-10-11 \mathrm{~g} / \mathrm{g}$ in a material sample and it is possible to study very small volumes of substances and materials, as well as to analyze the smallest grains of powders, and the simplicity and speed, many times exceeding the speed of chemical analysis [14] is also an advantage.

The studies were carried out on samples of treated and untreated Baltic succinite (table 2).

Table 2. Morphology samples of succinite of Palmniken Deposit for fluorescent analysis

\begin{tabular}{|c|c|c|c|c|c|c|}
\hline \multirow{3}{*}{$\begin{array}{l}\mathrm{n} / \\
\mathrm{a}\end{array}$} & \multicolumn{5}{|c|}{ Description } & \multirow{3}{*}{ Samples photos } \\
\hline & \multicolumn{4}{|c|}{ Morphology } & \multirow{2}{*}{$\begin{array}{l}248 \mathrm{x} \\
\text { Magnificatio } \\
\mathrm{n} \text { of samples }\end{array}$} & \\
\hline & Description & $\begin{array}{l}\text { Dimensi } \\
\text { ons, mm }\end{array}$ & Color & $\begin{array}{l}\text { Transpare } \\
\text { ncy, Shine }\end{array}$ & & \\
\hline 1. & $\begin{array}{l}\text { the shape of a parallel- } \\
\text { epiped with chamfers } \\
\text { on the perimeter of the } \\
\text { front side, the surface is } \\
\text { polished, uniform } \\
\text { transparency, there are } \\
\text { internal scaly cracks in } \\
\text { different directions } \\
\text { about } 3 \mathrm{~mm} \text { in diame- } \\
\text { ter, without external } \\
\text { damage and traces of } \\
\text { oxide. }\end{array}$ & $25 \times 10 \times 3$ & $\begin{array}{l}\text { Rich } \\
\text { honey } \\
\text { yellow, } \\
\text { uniform }\end{array}$ & $\begin{array}{l}\text { Transpare } \\
\text { nt, glass } \\
\text { luster }\end{array}$ & & \\
\hline 2. & $\begin{array}{l}\text { forms drop-shaped, } \\
\text { polished surface, } \\
\text { transparent, sometimes } \\
\text { light turbid, without } \\
\text { external damage and } \\
\text { traces of oxide }\end{array}$ & $6 \times 4 \times 3$ & $\begin{array}{l}\text { Rich } \\
\text { honey } \\
\text { yellow, } \\
\text { uniform }\end{array}$ & $\begin{array}{l}\text { Transpare } \\
\text { nt, glass } \\
\text { luster }\end{array}$ & : & \\
\hline 3. & $\begin{array}{l}\text { irregular shape, one } \\
\text { side has a cut, the } \\
\text { surface is polished, the } \\
\text { rest of the surface is } \\
\text { crusted }\end{array}$ & $\begin{array}{l}100 \times 64 \times 3 \\
5\end{array}$ & $\begin{array}{l}\text { Light } \\
\text { yellow }\end{array}$ & $\begin{array}{l}\text { Cloud, } \\
\text { glass, } \\
\text { glitter } \\
\text { wax, no } \\
\text { crust }\end{array}$ & & - \\
\hline
\end{tabular}




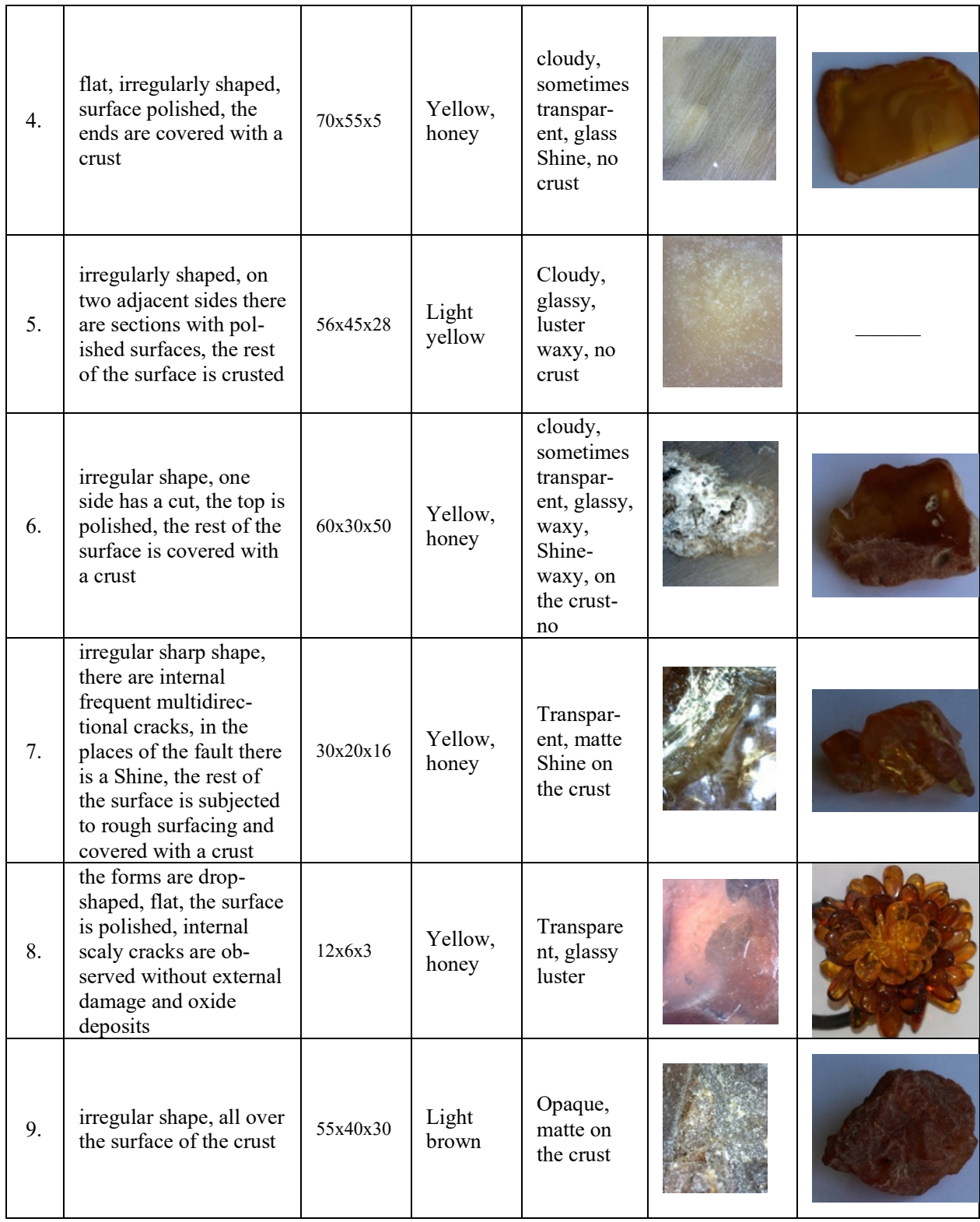

\section{Results}

The results of microscopic examination showed that the transparency of amber is influenced not only by the number, size and density of air bubbles, but also by the process of formation and solidification of amber resin, i.e. the flow in the form of flows forms a nonuniform anisotropic structure. Also as a result of the conducted research it is established that at mechanical processing of amber from air bubbles in a material both on a surface, and in a material mechanical cracks are formed, integrity of structure of a material is broken that starts process of oxidation - destruction in the form of formation of an opaque crust (table 3). The results of microscopic examination showed that when conducting a study on samples of untreated amber, having on the one hand a mechanical section, the results 
showed that the intensity and nature of the glow was not identical (table 4). There were differences in the color of the glow and their intensity (Fig. 1). A characteristic glow of yellow and partly blue at the edges was observed on the sample section (Fig. 1A), while on the back of the raw side intense glow-blue, greenish, pale yellow (Fig. 1B). A clear oxide layer with a blue glow was observed on the cut of the amber sample (Fig. 1A), the color of which is observed on the raw side (Fig. B) spread over the surface with different intensities, while the intensity of the yellow color decreased to a pale yellow, almost white.

Table 3. Microscopy samples of succinite of Palmniken Deposit

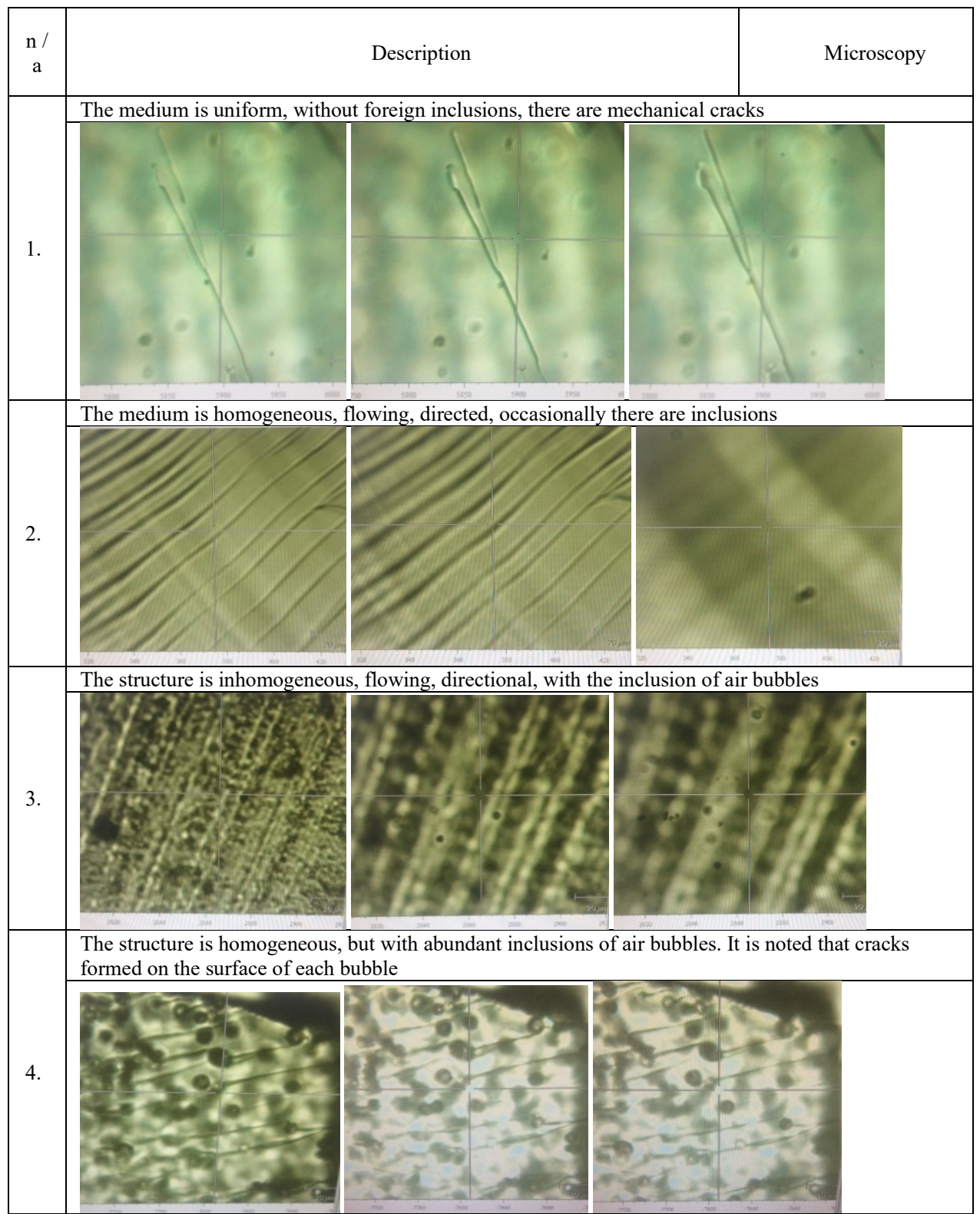


The greenish hue of the glow is a characteristic feature of the mixing of blue and yellow colors, which allows us to make an assumption about the uneven formation of the oxide layer, which is highly dependent on the environment and conditions. From the obtained observations, it can be assumed that by further analysis, calculation data obtained and comparison of intensity based on the laws of Cytoxa-Lommel and Vavilov's law, it is possible to obtain estimates about the date of manufacture of the product by comparing the intensity of the analysed and reference sample.

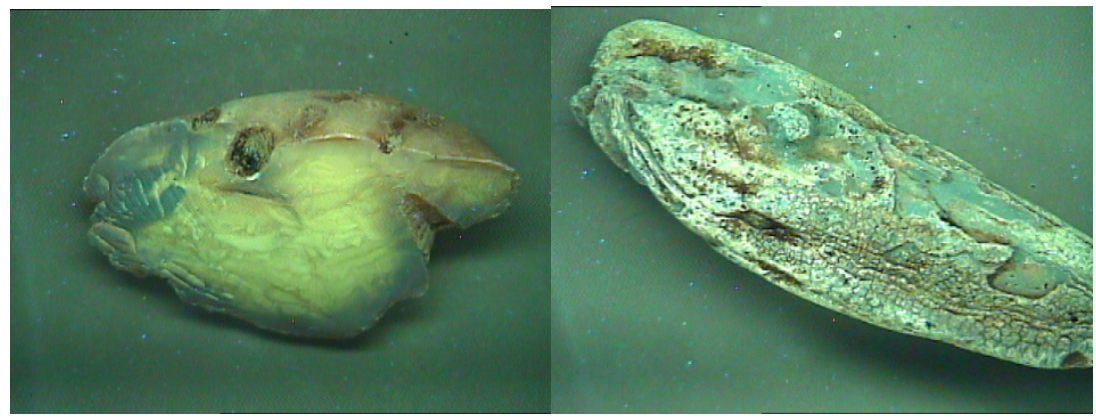

a

б

Fig. 1. Blue luminescence color of untreated Baltic succinite.

Table 4. Luminescence color samples of succinite of Palmniken Deposit

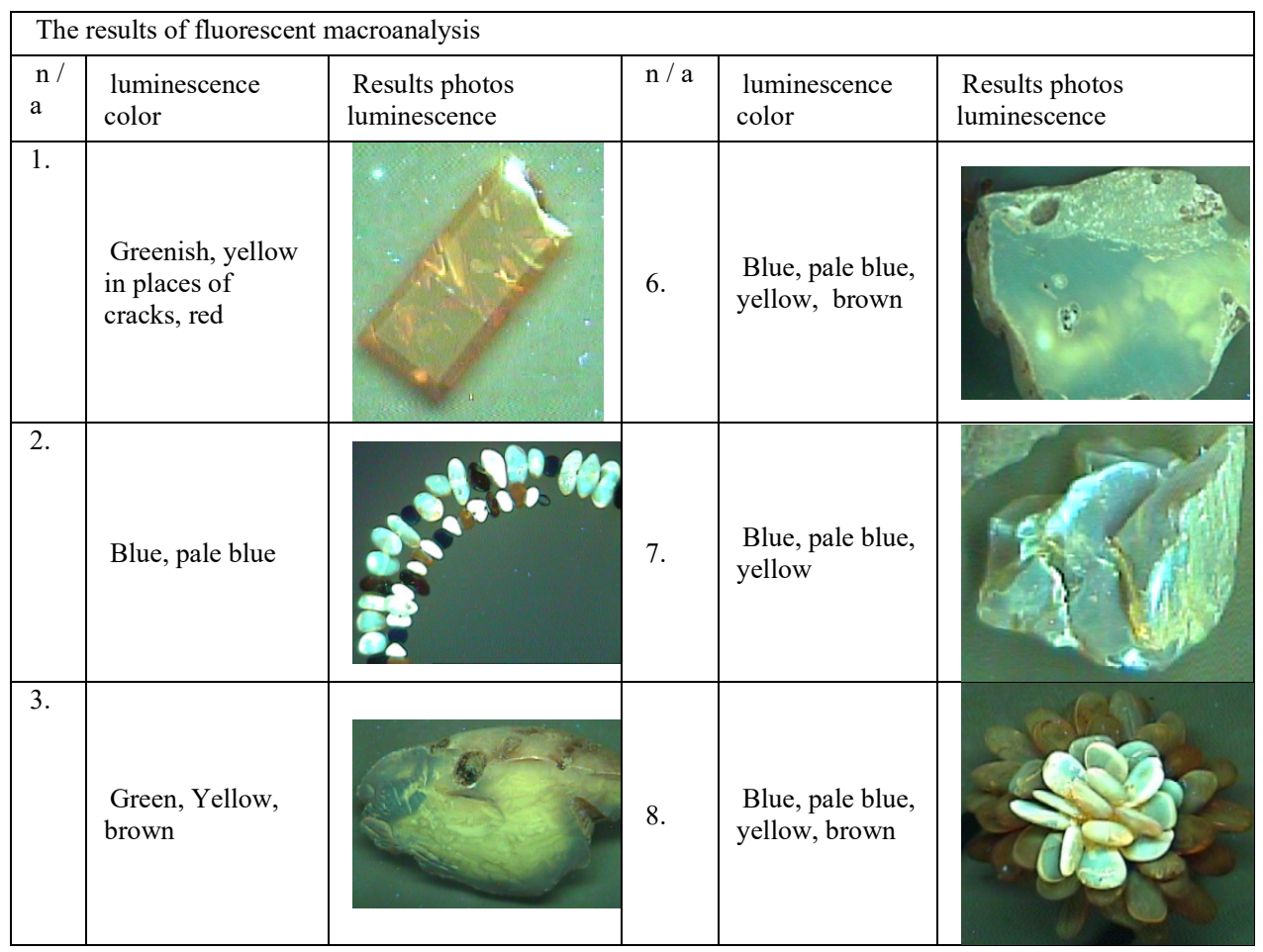




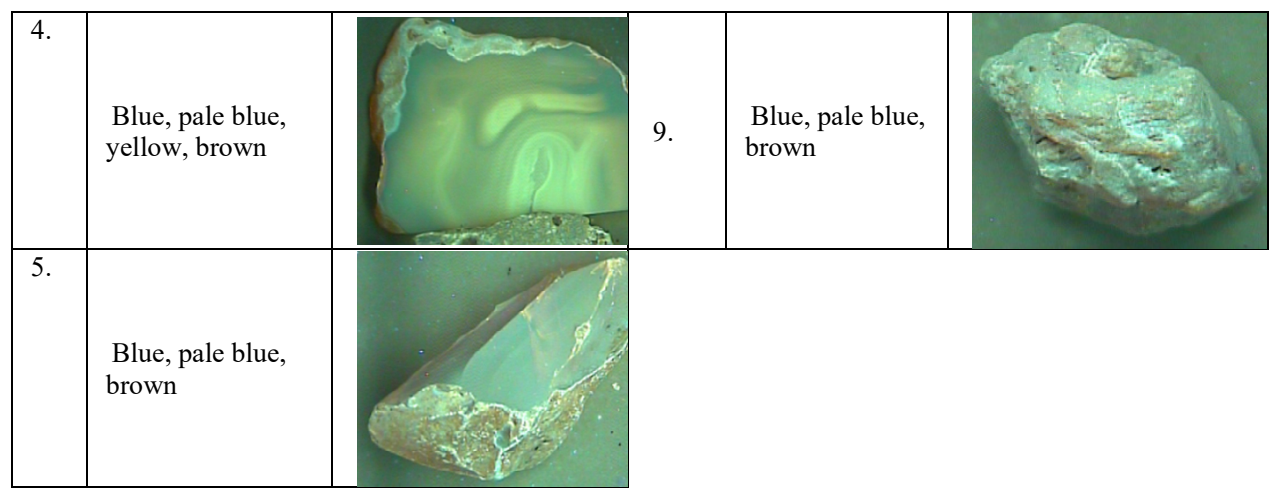

\section{Discussion}

- $\quad$ it is established that the processes of destruction of the surface of products made of untreated and treated succinite have different nature, in the second case it is accelerated by microcracks formed from the center of voids of air bubbles;

- $\quad$ it is revealed that the transparency of amber depends not only on the number, density and size of air bubbles, but also on the process of formation of flow, forming a nonuniform anisotropic structure;

- $\quad$ it is established that the intensity, color of luminescent glow or its combination allows to carry out flaw detection of materials and products from amber, i.e. to define heterogeneity of structure and a structure (samples 2, 8 tab. 4), internal and external defects on transparent and semi-transparent samples (samples 1, 7 tab.4);

- it was found that the study of amber with "weathered" surface crust luminescent method of analysis on samples 3-7 (tab. 4) observed pronounced boundaries of the crust, allowing to measure the thickness and calculate the duration of the time of its formation;

- $\quad$ it is established that the characteristic of amber transparency can be the color of the glow, namely from blue to brown, respectively, from transparent to opaque;

- $\quad$ it is established that as a result of the process of formation of the surface crust, the color and intensity of the glow change, which requires further research, the results of which will be useful in determining the time and place of origin of the material or product;

- $\quad$ it is established that as a result of the study of sample 1 (tab. 4) there is a lack of characteristic a transparent amber blue mode, therefore, because we know that this piece of amber under-subjected to heat treatment, it is possible to conclude that using fluorescent analysis may reveal that the impact on the color and transparency of amber heat treatment under confirmed through the study of sample 8, which are examples of thermally treated and untreated, respectively, with characteristic colors and luminescence intensity;

- It is established that the distinctive luminescence intensity at the defect boundaries is a characteristic of the presence of internal defects of the material and indicates the location of internal fractures, microcracks and other mechanical damage.

\section{Conclusion}

Based on the analysis results of the research can be concluded that knowing the approximate velocity of the flowing process of formation of the "weathered" crust, possible to pre- 
calculate the date of manufacture of the product, i.e. the thickness of the formed crust may serve as data to determine the time of manufacture of the product to the applied processing methods and surface protection.

Characteristics of the rate of quenching luminescent glow in the study of amber samples, which characterizes the efficiency of the transformation of exciting light into luminescence light and sensitive to external influences and destruction of the material, can be used as a basis for the selection of optimal operating conditions, storage of products made of polymer materials of organic origin, subject to destructive processes.

When identifying, attributing and authenticating amber materials, distinctive optical characteristics can be used: the duration of the excited state, the luminescence rate, i.e. fluorescence, and its intensity.

\section{References}

1. K. B. Anderson, J.Org. Geoch., 25, 3-4, 251-253 (1996)

2. S. S. Savkevich, N. (1970)

3. B. Serdobolsky, N. (1964)

4. K.B., Anderson, J.C. Crelling, J. A. Ch. S..170-192 (1995)

5. G. Shi, D. A., Grimaldi ... \& Li, X., J. Cr. R., 37, 155-163 (2012)

6. A.V., Alekseeva, L.A., Samarina, J.Ch. .N. C. 2, 6, 351-356 (1968)

7. Y.A., Golubev, O.V.,Martirosyan, 39, 3, 247-258 (2012)

8. T.,Urbański, W., Molak, J. Chemistry, 32, 1-2, 3-8 (1984)

9. J. Mills, J. Ch. G., 47, 1-2, 15-39 (1984)

10. L. J.,Gough, J. S.,Mills, J. Nat., 239, 5374, 527-528 (1972)

11. M., Guiliano, L. Asia, G. Onoratini, G. Mille, J. Spec. A. P. A: M.\& B. Sp., 67, 5, 1407-1411 (2007)

12. A.,Matuszewska, M.,Czaja, J. T., 56, 6, 1049-1059 (2002)

13. G. S. Landsberg, N. (1985)

14. K. B. Anderson, J. Org. Geo., 25, 3-4, 251-253, (1996) 